\title{
Por uma prática de leitura e escrita: uma experiência com o gênero fábula
}

\section{For a practice of reading and writing: an experience with the gender fábula}

Jeane Maria Gomes Favorino Universidade Estadual de Feira de Santana

Feira de Santana, Bahia Brasil

Alana de Oliveira Freitas El Fahl Universidade Estadual de Feira de Santana

Feira de Santana, Bahia Brasil

\begin{abstract}
Resumo: O presente artigo apresenta e discute os resultados de uma proposta de intervenção pedagógica, por meio de sequência didática, aplicada na Escola Estadual Antônio Carlos Pedreira, localizada no município de São Gonçalo dos Campos, no Recôncavo Baiano. A proposta teve como objeto de ensino a mobilização do gênero fábula, visando proporcionar aos alunos do $6^{\circ}$ ano do Ensino Fundamental II oportunidades para desenvolver sua competência discursiva. Defendemos as fábulas como um gênero textual/discursivo a ser trabalhado em sala de aula, pois, além de serem breves, transformam-se ao longo do tempo, permitem diversas maneiras de explorá-las e proporcionam discussões sobre diversas áreas de nossas práticas sociais. Os resultados obtidos evidenciam que, quando bem estimulados, os alunos conseguem desenvolver competências comunicativas para dentro e fora da sala de aula.
\end{abstract}

Palavras-chave: Sequência didática. Fábulas. Leitura. Escrita.

\begin{abstract}
The present article presents and discusses the results of a proposal of pedagogical intervention, through a didactic sequence, applied at the Antônio Carlos Pedreira State School, located in the municipality of São Gonçalo dos Campos, in the Recôncavo Baiano. The purpose of this proposal was to mobilize the fable genre, aiming to provide the students of the 6th grade of Elementary School with opportunities to develop their discursive competence. We advocate fables as a textual / discursive genre to be worked in the classroom, as they are not only brief, they transform over time, they allow diverse ways of exploring them, and they provide discussions about various areas of our social practices. The results show that, when stimulated, students can develop communicative skills in and out of the classroom.
\end{abstract}

Keywords: Didactic sequence. Fables. Reading. Writing.

\section{PARA INÍCIO DE CONVERSA...}

Este artigo é resultado do projeto de pesquisa intitulado O Fantástico Mundo das Fábulas: uma intervenção para o ensino de leitura e escrita, aplicado no primeiro semestre de 2016, na turma do $6^{\circ}$ ano A da Escola Estadual Antônio Carlos Pedreira, do município de São Gonçalo dos Campos, situado no interior da Bahia. Este trabalho se caracteriza como

* Mestre em Letras pelo curso de Mestrado Profissional em Letras da Universidade Estadual de Feira de Santana. jeanefavorino1@gmail.com

**Doutora em Teorias e Críticas da Literatura e da Cultura pela Universidade Federal da Bahia. Professora Titular de Literatura Portuguesa e Brasileira da Universidade Estadual de Feira de Santana. Email: alanafreitasfahl@gmail.com. 
uma pesquisa qualitativa, com enfoque na pesquisa-ação, visando interferir na prática de sala de aula, através de um projeto de intervenção pedagógica de leitura e escrita, com base na sequência didática que foi adaptada da proposta apresentada por Dolz, Noverraz e Schneuwly (2010), e foi pré-requisito para obtenção do título de Mestre do Curso de Mestrado Profissional em Letras - PROFLETRAS -, da Universidade Estadual de Feira de Santana - UEFS, turma de 2014.

Embora o ensino de Língua Portuguesa tenha atingido um avanço significativo nas práticas de sala de aula, com a publicação dos Parâmetros Curriculares Nacionais, no final da década de 90 , que trouxeram um novo direcionamento para o ensino de língua materna, estabelecendo o texto como unidade de ensino e os gêneros textuais como objeto de ensino, verificamos que, na maioria das vezes, as práticas de sala de aula ainda não têm dado conta de desenvolver no educando as competências comunicativas que lhes são necessárias dentro e fora da escola. Assim, o desenvolvimento das competências discursivas dos educandos, continua sendo um dos grandes desafios dos profissionais de educação, especialmente dos professores de língua materna. Dessa forma, nosso projeto de intervenção pedagógica foi planejado em formato de Sequência Didática, com atividades que foram pensadas com o intuito de permitir que os alunos ultrapassaem seus próprios limites, em direção ao desenvolvimento de sua competência comunicativa oral e escrita. Para tanto, valemo-nos de estratégias que viabilizaram um estudo cooperativo e colaborativo, a fim de favorecer a interação e o desenvolvimento da competência leitora e escritora dos sujeitos da pesquisa.

Apostamos nas fábulas como objeto de ensino para o $6^{\circ}$ ano, por partilhamos do pensamento de Cosson (2014), que afirma que a literatura serve tanto para ensinar a ler e escrever quanto para formar culturalmente o indivíduo. O letramento literário não é apenas a aprendizagem da leitura de textos literários e sim da compreensão, da reflexão, da formação de consciência crítica, da construção de sentidos do que lê, do mundo à sua volta. A fábula é um gênero literário breve, capaz de suscitar o interesse da criança pelo assunto através do fantástico. Ao aguçar sua imaginação do estudante, sua criatividade e senso crítico, as fábulas deram oportunidades para o aluno fazer inferências, relacionar a temática a questões pessoais, políticas, sociais, culturais, identificar as ideias presentes nas entrelinhas e compartilhar saberes. Não pretendíamos, com o trabalho com as fábulas, formar fabulistas, mas, partindo de um gênero que os alunos já conheciam, viabilizar o desenvolvimento de sua competência discursiva.

\section{A ESCOLA E A FORMAÇÃO DO LEITOR/ESCRITOR}

Muito se tem falado, nos últimos anos, sobre o desenvolvimento da competência leitora dos alunos. Entretanto, o que é ser um leitor competente? Acredito que para respondermos a essa pergunta, uma outra precisa ser esclarecida: O que é competência leitora? 
De acordo com o documento oficial da OCDE/PISA ${ }^{1}$, a competência leitora "consiste na compreensão e no emprego de textos escritos e na reflexão pessoal a partir deles, com a finalidade de atingir metas próprias, desenvolver o conhecimento e o potencial pessoal e de participar da sociedade”. Assim, leitor competente é aquele que é capaz de interagir com o texto, atribuindo-lhe sentidos, que é capaz de dominar as práticas sociais de leitura e escrita, e que, "a partir de hipóteses, de predições levantadas, vai além do que está explícito, do que está declarado" (ANTUNES, 2013, p. 204). Conduzir os alunos pelos caminhos da leitura, a fim de torná-los leitores competentes, tem sido o grande desafio do professor, sobretudo na última década do século XX, com a publicação dos Parâmetros Curriculares Nacionais (1998), que conceituam o leitor competente como aquele que

[...] sabe selecionar, dentre os textos que circulam socialmente, aqueles que podem atender a suas necessidades, conseguindo estabelecer estratégias adequadas para abordar tais textos. $\mathrm{O}$ leitor competente é capaz de ler as entrelinhas, identificando, a partir do que está escrito, elementos implícitos, estabelecendo relações entre o texto e seus conhecimentos prévios ou entre o texto e outros textos já lidos (BRASIL, 1998, p. 70).

É importante que a escola favoreça, por meio de práticas variadas de leitura e escrita, o desenvolvimento dessa competência leitora para dentro e fora da sala de aula, tornando o aluno capaz de atingir novos horizontes, traçar novos objetivos, construir novos significados para o mundo à sua volta. Entretanto, isso não se faz apenas ensinando o aluno a ler e escrever, mas garantindo-lhe o direito de apropriar-se da escrita e das práticas sociais relacionadas a ela. É com o propósito de conferir aos estudantes o direito à leitura e à escrita que a escola deve pensar no texto como meio pelo qual a língua se manifesta. No que se refere a proposta do nosso projeto, partimos do princípio de que o texto é "a unidade máxima de funcionamento da língua” (MARCUSCHI, 2015, p. 88); um instrumento de interação social entre os homens.

É sabido que nunca se leu e se escreveu tanto como nos dias de hoje com o advento das novas tecnologias de comunicação e informação. No entanto, o que se percebe é que a maioria de nossas escolas ainda não encontrou o caminho para formar leitores e escritores profícuos. Neste artigo, destacam-se alguns pontos que nortearam uma proposta de intervenção. A saber:

A) O lugar do texto na sala de aula - é bastante comum encontrarmos alunos com dificuldades de se expressar, expor suas ideias, ou resumir ideias contidas em um texto, porque não foram acostumados a trabalhar de maneira significativa com o mesmo em sala de aula, onde, na maioria das vezes, preconiza-se o estudo exaustivo da gramática com o uso do texto para fins metalinguísticos. No entanto, se pensarmos na língua como sistema pelo qual se estabelece a interação entre os sujeitos, nas suas mais variadas práticas sociais, e que ela só acontece em textos, outro não poderá ser o lugar dado ao texto em nossas

${ }^{1}$ A Coordenação para a Cooperação e Desenvolvimento Econômico (OCDE), que congrega os 30 países mais ricos do mundo, coordena o Programme for International Studant Assessment (PISA), que em Português quer dizer Programa Internacional de Avaliação de Alunos, tendo em vista melhorar as políticas públicas e resultados educacionais. 
aulas de língua que não o centro do processo de ensino, visto que é a partir desse projeto de dizer que os discursos se materializam. Contudo, não queremos dizer aqui que a gramática deve ser deixada de fora; sabemos sim que ela é necessária, mas não suficiente, para o fortalecimento da competência discursiva do aluno.

B) A importância da concepção de leitura adotada pela escola - Ler consiste em atribuir sentido. Segundo Silva (2015, p. 22), "ler é um ato da interação à distância perpassado pela vivência do leitor que, em última instância, constrói um sentido para o texto". Isso significa que ler é atribuir significado, sentido àquilo que é lido o resultado da relação autor/leitor, mediada pelo texto. O texto terá tantas leituras quantas forem as experiências vivenciadas pelo(s) leitor(es). A escola, como instituição responsável pelo desenvolvimento da capacidade de leitura dos alunos, precisa definir claramente a concepção de leitura que pretende adotar. Kleiman (2000, p. 30) afirma que, no contexto escolar, "a atividade de leitura é difusa e confusa, muitas vezes se constituindo apenas em um pretexto para cópias, resumos, análise sintática, e outras tarefas do ensino da língua”. Tais atividades não despertam no aluno o interesse e o gosto pelo ato de ler. Por isso, adotamos a concepção de leitura enquanto atividade dialógica, como prática social, responsável por encontros de interação entre autor-texto-leitor, concepção esta, apresentada por Koch (2011) - leitura com foco na interação autor-texto-leitor, que, em lugar de manter o foco no autor ou no texto, põe o foco na relação entre os três (autor, texto e leitor), que juntos vão construindo o sentido do texto. Assim sendo, propusemos nesta intervenção pedagógica atividades que favoreceram esse movimento dialógico no processo interativo da leitura, uma vez que abriu espaço para que o aluno expusesse suas impressões sobre o texto lido, interpretando, analisando e criticando, a partir de suas vivências, as ideias aí expressas, .

C) A leitura do texto literário como uma perspectiva para o letramento - em uma sociedade letrada como a nossa, a escrita faz parte da vida de todos os indivíduos, novos ou anciãos; cultos ou indoutos. Enquanto que para uns ela pode significar passaporte para o mundo ao qual se almeja, para outros, ela é o entrave, o obstáculo que os impede de descobrir novos mundos, ocupar outros lugares. No entanto, parafraseando Soares (2004), não basta, à escola, apenas ensinar o indivíduo a ler e escrever; é preciso proporcionar-lhe a aquisição de competências, envolvendo-o em práticas sociais de leitura e escrita a que chamamos de letramento. Para Soares (2004), letramento é o "estado ou condição de quem não apenas sabe ler e escrever, mas cultiva e exerce as práticas sociais que usam a escrita e a leitura". É nessa perspectiva de letramento que deve trabalhar a escola, buscando favorecer momentos variados de práticas de leitura e escrita. Apostamos na perspectiva do letramento literário por acreditarmos que "o letramento feito com textos literários proporciona um modo privilegiado de inserção no mundo da escrita, posto que conduz ao domínio da palavra a partir dela mesma." (COSSON e SOUZA in: http://migre.me/tJZ8Z). O trabalho com o texto literário, se bem estruturado, contribui para alimentar a imaginação; despertar sentimentos; desenvolver a criatividade, a criticidade; para o reconhecimento de si e do outro; e para ampliar a capacidade de compreensão do mundo. 
D) Algumas considerações para o trabalho com a escrita em sala de aula - trabalhar com a escrita em sala de aula é um dos grandes cuidados que deve ser observado por uma proposta de ensino que visa ao desenvolvimento da competência discursiva do aluno. Sabemos que a escrita é uma atividade cuja realização demanda o conhecimento sobre o que se pretende escrever, bem como o uso de várias estratégias no curso de sua produção. Assim, consideramos em nossa intervenção atividades que valorizaram a discussão prévia do assunto antes da produção, com o intuito de subsidiar, instrumentalizar os alunos para escrita, por compartilharmos com Antunes (2013, p. 45) - e não poderia ser diferente que ter o que dizer é condição prévia para o êxito da atividade de escrever. Definir as condições de produção é igualmente importante. $\mathrm{O}$ aluno precisa conhecer a função social da escrita, pois escrevemos sempre com algum propósito: convencer, anunciar, informar, convidar, denunciar etc. Atrelada à dimensão da funcionalidade está a dimensão da troca, da partilha com o outro; o texto se concretiza no outro. É preciso saber para quem se escreve; o texto se realiza de acordo com seu interlocutor. A escolha pelo registro mais indicado, em função da natureza comunicativa, define-se de acordo com o interlocutor: quanto mais o produtor do texto conhece seu leitor, melhor será o produto final.

\section{A FÁBULA E SUAS POSSIBILIDADES PEDAGÓGICAS}

O que esperam a família e a sociedade da escola? Arriscamo-nos a dizer que o bom desempenho dos alunos em leitura e escrita de textos. Que os estudantes saibam se expressar de maneira clara e objetiva nas diversas situações de uso da linguagem. Assim, para darmos início ao nosso trabalho como os alunos do $6^{\circ}$ ano, foi proposto um "primeiro" encontro, enquanto pesquisadora, com uma roda de conversa e aplicação de questionário, a fim de tomarmos conhecimento da relação dos sujeitos da pesquisa com a cultura escrita, com a escola e suas condições sociais. Essa atividade serviu de base para a elaboração do plano de intervenção, respeitando as necessidades de aprendizagem dos alunos.

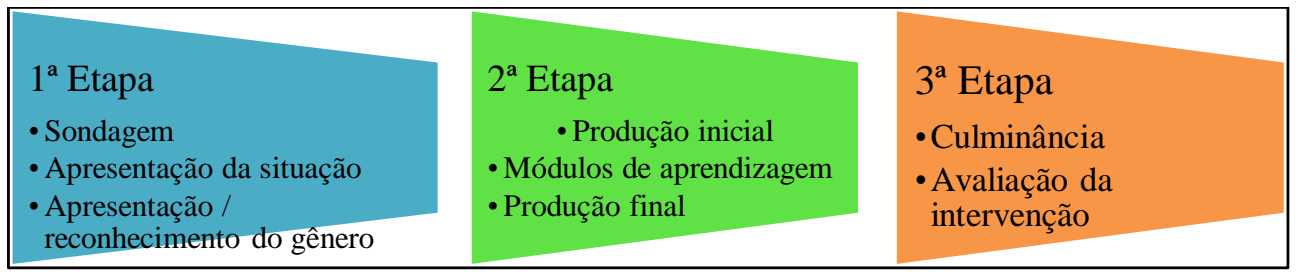

Figura1: Etapas da Intervenção

Fonte: Elaborada pela pesquisadora

Em nosso plano de ação, distribuímos as atividades em 7 oficinas (essas oficinas não incluem a sondagem, a apresentação da situação, a culminância e a avaliação da intervenção), num total de $24 \mathrm{~h}$ /aulas, porque algumas delas exigiram mais encontros. $\mathrm{O}$ modelo utilizado foi uma adaptação da Sequência Didática apresentada por Dolz, Noverraz e Schneuwly (2010), produzido e apresentado pelo Professor Doutor Patrício Nunes Barreiros nas aulas da disciplina Texto e Ensino, no âmbito do Profletras, 
inserindo nela alguns passos sugeridos por Costa-Hübes e Simioni (2007) e, para essa intervenção, seguimos o esquema da Figura 01.

As atividades para a intervenção foram organizadas conforme o resumo apresentado no quadro 1:

\begin{tabular}{|c|c|}
\hline DIA/MÊS & ATIVIDADES \\
\hline $23 / 03$ & Sondagem com roda de conversa e aplicação de questionário. \\
\hline $29 / 03$ & $\begin{array}{l}\text { Apresentação da situação através de slides; ficou claro que, ao final do } \\
\text { projeto, eles produziriam um livro de fábulas para ser distribuído entre } \\
\text { eles, professores e funcionários da escola, bem como publicado no Face- } \\
\text { book da escola. } \\
\text { Leitura, esclarecimentos e assinatura de Termo de Assentimento Livre } \\
\text { Esclarecido. }\end{array}$ \\
\hline $05 / 04$ e $12 / 04$ & $\begin{array}{l}\text { Apresentação/reconhecimento do gênero através de leitura, discussões } \\
\text { das ideias do texto e identificação das características da fábula. } \\
\text { Identificação da fábula entre outros gêneros. }\end{array}$ \\
\hline $19 / 04$ e $26 / 04$ & $\begin{array}{l}\text { Produção inicial a partir da leitura e discussão de uma fábula com o tema } \\
\text { da proposta de produção. } \\
\text { Dinâmica para a escolha e composição dos personagens. }\end{array}$ \\
\hline $03 / 05$ & $\begin{array}{l}\text { Módulo I - revisão coletiva de alguns textos da produção inicial } \\
\text { Produção coletiva. }\end{array}$ \\
\hline $10 / 05$ e $24 / 05$ & $\begin{array}{l}\text { Módulo II - identificação e sistematização das características do gênero a } \\
\text { partir da leitura de fábulas e discussão das ideias do texto. }\end{array}$ \\
\hline $13 / 06$ e $14 / 06$ & $\begin{array}{l}\text { Módulo III - comparação das versões de uma mesma fábula através da } \\
\text { leitura de versões da A raposa e as uvas escritas por Esopo, Millôr Fer- } \\
\text { nandes, Monteiro Lobato e Jô Soares. } \\
\text { Leitura e escolha de fábulas para dramatização. } \\
\text { Preparação para a dramatização }\end{array}$ \\
\hline $05 / 07$ & $\begin{array}{l}\text { Produção final - a partir da leitura e discussão de uma fábula que forne- } \\
\text { ceu subsídios para a produção do texto final dos alunos }\end{array}$ \\
\hline $11 / 07$ e $12 / 07$ & Ensaio e apresentação das fábulas \\
\hline $01 / 08$ & $\begin{array}{l}\text { Culminância - contação de história feita por uma educadora convidada; } \\
\text { discussão sobre o texto ouvido; esclarecimento sobre a relevância do tra- } \\
\text { balho produzido por eles; entrega dos exemplares e autógrafos }\end{array}$ \\
\hline$\overline{02 / 08}$ & Avaliação da intervenção didático-pedagógica através de questionário. \\
\hline
\end{tabular}

Quadro 1: Avaliações 
Para aplicação da sequência didática, foi elaborado um material pedagógico com atividades com o tex to que não se limitaram apenas à compreensão, mas que abrangeram também a produção textual. Para isso, mobilizando o gênero fábula, teve-se o cuidado de buscar textos de alguns autores do gênero que abarcassem assuntos interessantes ao aluno nessa etapa de seu desenvolvimento, bem como a nossa história atual (estávamos em ano de eleições municipais). Privilegiaram-se produções que permitissem a discussão, a troca de ideias e saberes em sala de aula e que atendessem às orientações do PNLD (Programa Nacional do Livro Didático) 2017. Assim sendo, selecionamos textos que permitiram discussões acerca da valorização do outro e de si mesmo, respeitando as diferenças, e que fomentaram discussões a respeito da participação do cidadão no desenvolvimento no país. Ainda sobre as orientações do PNLD 2017, buscamos promover a integração das tecnologias ao trabalho escolar.

Com o intuito de apresentar aos nossos alunos um material que correspondesse às demandas e necessidades $\mathrm{da}$ comunidade escolar e propusesse um trabalho cooperativo/colaborativo em sala de aula, pensamos em atividades que viabilizassem a interação, a reflexão crítica, a troca de ideias, a expansão do sentido atribuído ao texto. Para tanto, adotamos a concepção de língua como o meio de interação do indivíduo consigo mesmo, com o outro e com sua história, por partilharmos com Antunes (2013, p. 49) o conceito de que "a linguagem é uma forma de agir socialmente, de interagir com os outros, e de que essas coisas somente acontecem em textos".

Assim, primamos por trabalhar o texto em sala de aula contemplando atividades que observassem os descritores de Língua Portuguesa para a compreensão textual no Ensino Fundamental, dispostos na Matriz de referência proposta pelo SAEB (Sistema Nacional de Avaliação da Educação Básica) ${ }^{2}$, valendo-se, no momento, de alguns daqueles que atendem às demandas do $6^{\circ}$ ano do Ensino Fundamental II. Contudo, vale salientar que, apesar de representarem um avanço muito grande no que diz respeito ao trabalho com o texto, os descritores não dão conta de todas as demandas da sala de aula, , não contemplando, por exemplo, o trabalho com a produção textual que foi um dos focos desta intervenção.

Para o momento, foram selecionados os seguintes descritores:

\section{Do tópico I. Procedimentos de leitura}

D1 - Localizar informações explícitas em um texto.

D3 - Inferir o sentido de uma palavra ou expressão.

D4 - Inferir uma informação implícita em um texto.

D6 - Identificar o tema de um texto.

D11 - Distinguir um fato da opinião relativa a esse fato.

Do Tópico II. Implicações do Suporte, do Gênero e/ou do Enunciador na Compreensão do Texto

D9 - Identificar a finalidade de textos de diferentes gêneros.

Do Tópico IV. Coerência e Coesão no Processamento do Texto

\footnotetext{
${ }^{2}$ Encontrada no livro Produção textual, análise de gêneros e compreensão (ano de publicação), de Luiz Antônio Marcuschi,, colocando o ano de publicação, essa informação pode ser excluída. .
} 

narrativa.

D7 - Identificar o conflito gerador do enredo e os elementos que constroem a

D8 - Estabelecer relação causa/consequência entre partes e elementos do texto.

D12 - Estabelecer relações lógico-discursivas presentes no texto, marcadas por conjunções, advérbios, etc.

Do Tópico V. Relações entre Recursos Expressivos e Efeitos de Sentido

D14 - Identificar o efeito de sentido decorrente do uso da pontuação e de outras notações.

\section{OS MÓDULOS DE APRENDIZAGEM...}

Os módulos de aprendizagem foram sendo construídos a partir dos dados levantados na produção inicial dos alunos sobre o gênero, o que norteou a construção de nossa sequência didática, e objetivaram trabalhar as dificuldades dos alunos encontradas na primeira produção, buscando instrumentá-los de maneira satisfatória, a fim de que pudessem superá-las.

O módulo I foi elaborado após a revisão de texto da produção inicial e previu atender às dificuldades de adequação temática, uso da margem, dos discursos diretos e indiretos e da construção dos parágrafos. Buscou-se, através da atividade ${ }^{3}$ proposta nesse módulo, discutir com os alunos as "alternativas da reconstrução do seu dizer" (ANTUNES, 2013, p. 162), e não os expor.

O módulo II previu, além da discussão do texto, o estudo das características do gênero, sua estrutura e marcas linguísticas. Nossas atividades e discussões levaram os alunos a identificarem a sequência da narrativa por meio de recursos linguísticos, evidenciando, assim, a relevância da gramática para a construção do sentido do texto. Entretanto, reiteramos que o estudo exaustivo da gramática não se faz suficiente para o desenvolvimento da competência discursiva do aluno. Para as atividades desde módulo, trabalhamos com os textos "A raposa e o macaco", de Esopo, e "O reformador do mundo", de Monteiro Lobato. A escolha desses textos, além dos objetivos já citados, deuse por dois motivos especiais. Abrir espaço para discussões sobre o momento que estávamos vivendo (as eleições municipais) e desconstruir a noção de que as fábulas só têm como personagem animais. Consoante Dezotti (2003, p.27),

A leitura das fábulas gregas mostra que já naquele tempo a fábula nunca se limitou apenas a trabalhar apenas com "histórias de animais que falam", como veiculam em nossos manuais. Notamos que qualquer ser podia constituir-se personagem de fábulas: ao lado dos animais, encontramos deuses, herói, homens, plantas, objetos, diferentes partes de um mesmo corpo e até entidades abstratas (DEZOTTI, 2003, p. 27).

\footnotetext{
3 Todas as atividades elaboradas e utilizadas na Sequência Didática podem ser encontradas na dissertação do Profletras - UEFS - intitulada O Fantástico Mundo das Fábulas: uma intervenção para o ensino de leitura e escrita (use itálico ou spas nos títulos. Use a mesma forma em todos os títulos. No quadro citado anteriormente, o título está em itálico; em outras passagens do texto, usaram-se aspas.
} 
A atividade elaborada para o módulo III visou mostrar para os alunos que existem várias versões de uma mesma fábula, algo que foi identificado desde o início de nossa intervenção. Segundo Dezotti (2003), a maleabilidade da forma das fábulas lhes permite incorporar novos repertórios de narrativas e ajustar-se à expressão de visões de mundo em diferentes épocas e, acrescento, diferentes lugares, visto o que acontece com as fábulas recriadas por autores brasileiros, que as adequaram à nossa realidade, acrescentando-lhes novos dados, como verificamos nas versões que trabalhamos de "A raposa e as uvas", fábula de Esopo reescrita por Millôr Fernandes, Monteiro Lobato e Jô Soares.

As atividades do módulo IV surgiram a partir das discussões das versões da fábula "A raposa e as uvas" trabalhadas no módulo anterior, no qual foi manifestado o interesse de alguns alunos em interpretar fábulas. Podemos considerar o módulo IV como o momento de produção artística. Nele, foram discutidos em equipes os textos que seriam dramatizados, selecionados o figurino e o cenário, e os alunos propuseram a confecção de máscaras para representar os animais dos textos.

Os módulos foram muito importantes para construção da nossa produção final, um livro de fábulas elaborado pela turma -, pois subsidiaram os alunos para escrever seus textos com mais segurança.

\section{OS RESULTADOS...}

Para verificarmos se o trabalho de intervenção pedagógica havia alcançado os objetivos de desenvolver a competência discursiva dos alunos do $6^{\circ}$ ano do Ensino Fundamental II, a partir da leitura, interpretação, discussão e produção de fábulas, fizemos uma análise comparativa entre a produção inicial e a produção final propostas em nossa SD. Para tanto, elaboramos um quadro característico do gênero fábula, de acordo com os aspectos abordados durante os encontros, a fim de objetivarmos a análise. Para a construção desse quadro, consideramos três características do gênero discursivo apresentadas por Bakhtin (2011): o conteúdo, o estilo e a estrutura. O foco de nossas análises recaiu sobre a dimensão global dos textos, os aspectos textuais mais relevantes para o desenvolvimento dessa competência. Os demais aspectos, no momento, receberam análise mais superficial, pois entendemos que também contribuem para melhor eficácia da produção. Assim, os textos foram analisados à luz do princípio de natureza aplicativa, proposto por Antunes (2013), que implica que todo ensino de língua tem por objetivo maior ampliar a competência comunicativa das pessoas.

Para o fim a que se propõe esse texto, que é o de apresentar e discutir os resultados de nossa pesquisa, trouxemos, como amostra, a análise da produção inicial e da produção final de um dos sujeitos de nossa pesquisa, identificado pela sigla RKM12 - a fim de preservarmos sua identidade - que corresponde à letra do nome, sexo e idade. 


\section{Revista \\ A Cor \\ das I etras}

Feira de Santana, v. 18, n. 3, p. 207-221, set.-dez. 2017

\section{Produção inicial}

\section{O Dei da seheo.}

Qrei do selno tod is temen die to deve ele se olimento de enne plixe onimoir ete mas consei do cono leâs \& a mither dele a a leoo les proteren

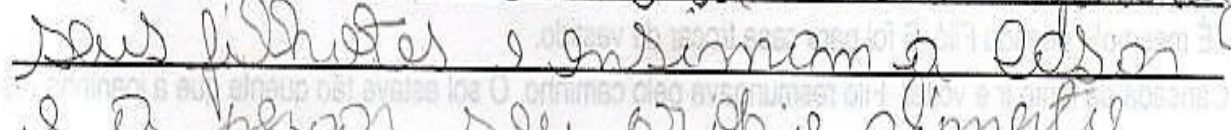
Q D perom seer orohio stimato e ele enprentio muites emimas

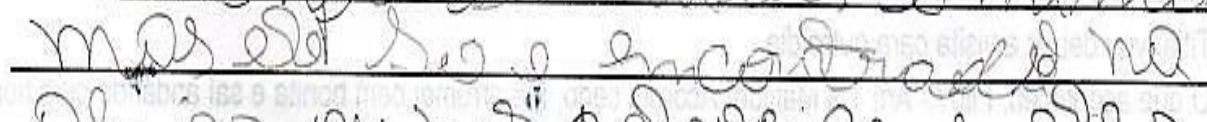

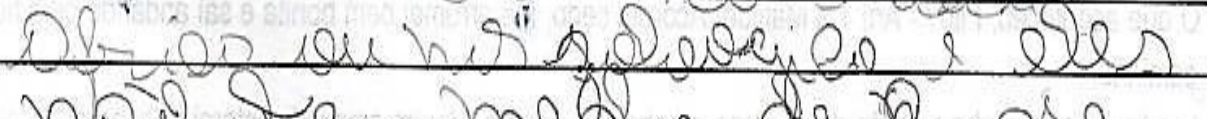
now Nom melo de auase node eles moltam medhe de hodo a es se retruenterm

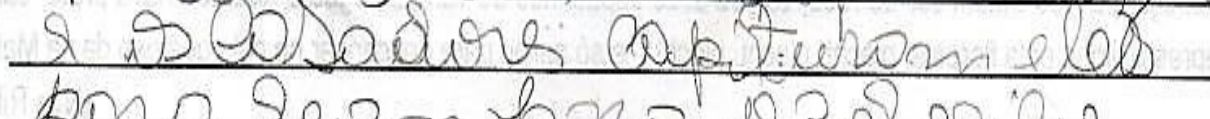
dena levar bono op, derile

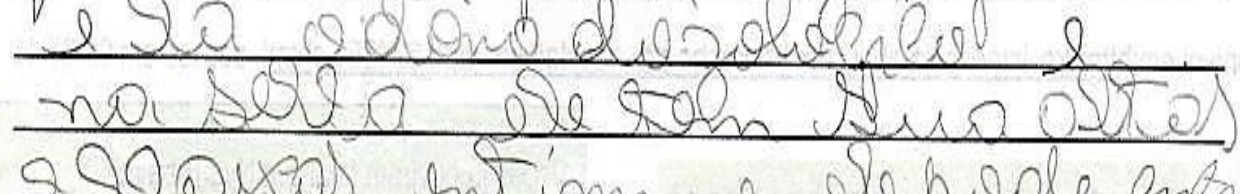

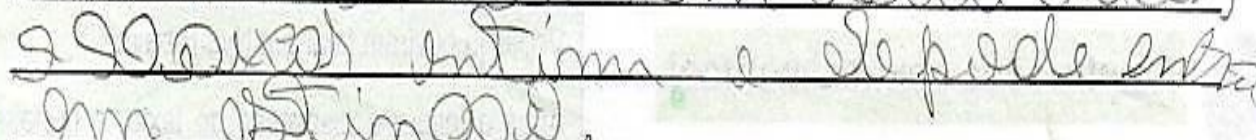
an asmones. 


\section{Revista

Produção final

\section{No Quintol do meu bule go}

Ho evintar de meu plepe timha musto

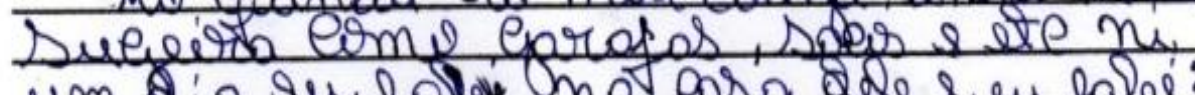

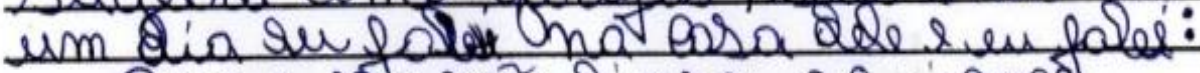
Poray vo no simpar of enintor?

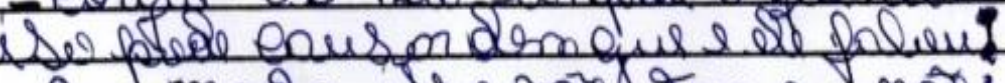

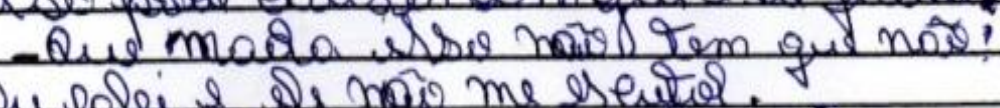

Sopois depois de osaus dias de fibur dente

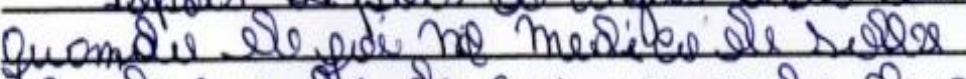

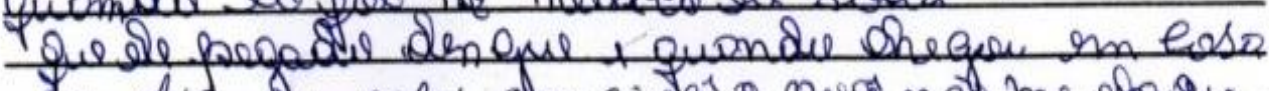

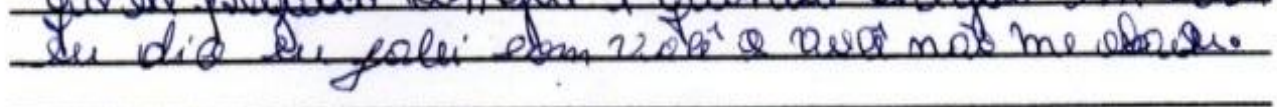

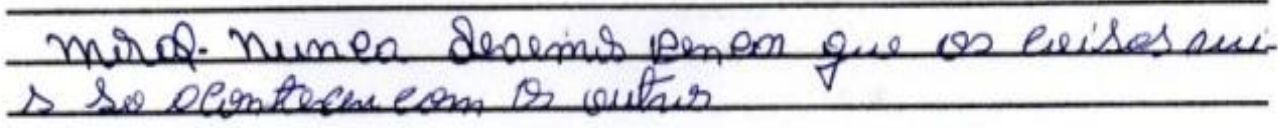




\begin{tabular}{|c|c|c|c|}
\hline Estudante & Características & Produção inicial & Produção final \\
\hline \multirow{8}{*}{ RKM12 } & Estrutura & $\begin{array}{l}\text { Descrição breve da } \\
\text { personagem } \\
\text { Sem moral explícita } \\
\text { Título formado por } \\
\text { referência à personagem }\end{array}$ & $\begin{array}{l}\text { Narrativa breve com } \\
\text { poucos personagens } \\
\text { Apresenta moral } \\
\text { Título formado por } \\
\text { referência à personagem }\end{array}$ \\
\hline & Tempo e espaço & Não apresenta & $\begin{array}{l}\text { Tempo impreciso } \\
\text { Espaço definido }\end{array}$ \\
\hline & Personagens & O leão & O narrador e o colega \\
\hline & Situação problemática & Não apresenta & $\begin{array}{l}\text { Apresenta situação de } \\
\text { conflito }\end{array}$ \\
\hline & Foco narrativo & Não apresenta & $\begin{array}{l}1^{\mathrm{a}} \text { pessoa - narrador } \\
\text { observador }\end{array}$ \\
\hline & Linguagem & Simples e objetiva & $\begin{array}{l}\text { Simples e objetiva, com o } \\
\text { uso do discurso direto }\end{array}$ \\
\hline & Conteúdo temático & $\begin{array}{l}\text { Apresenta uma } \\
\text { descrição fora do tema } \\
\text { proposto }\end{array}$ & $\begin{array}{l}\text { Apresenta uma narrativa } \\
\text { dentro do tema proposto }\end{array}$ \\
\hline & $\begin{array}{l}\text { Competência crítico- } \\
\text { discursiva }\end{array}$ & $\begin{array}{l}\text { Expõe características do } \\
\text { objeto }{ }^{4} \text { assinalando seus } \\
\text { traços mais salientes }\end{array}$ & $\begin{array}{l}\text { O texto expressa o } \\
\text { conteúdo de maneira } \\
\text { coerente, com sentido } \\
\text { construído a partir do } \\
\text { conhecimento } \\
\text { enciclopédico do autor }\end{array}$ \\
\hline
\end{tabular}

Quadro 2: Descrição das atividades.

O que observamos na comparação entre os textos de RKM12 é que há um crescimento considerável em relação à competência para escrita do aluno, especialmente no que diz respeito à tipologia textual. Em sua produção inicial, produzida antes da intervenção, o aluno constrói um texto descritivo, tendo como objeto de sua descrição, o leão. $\mathrm{O}$ aluno utiliza um dos personagens mais peculiares das fábulas, entretanto expõe suas caraterísticas assinalando seus traços mais destacados a partir de elementos que fazem parte de seu conhecimento enciclopédico. Na produção final, embora o sentido construído pelo autor não faça dela um exemplar da fábula, nota-se uma progressão desde a organização da estrutura do texto até seus aspectos discursivos e o entendimento da proposta de narrar. Sendo assim, a produção final de RKM12 apresenta um desenvolvimento nas competências para autoria, para a escrita de textos, para a funcionalidade comunicativa, categorias revisadas, de maneira mais detalhada, no aporte teórico de nossa dissertação.

Ao analisarmos os textos dos alunos, verificamos, de maneira geral, um progresso na capacidade de produzir textos, expondo suas ideias de maneira coerente, assumindo uma competência para autoria e a para a escrita de textos. Entretanto, os textos analisados dos alunos que fizeram parte do nosso recorte - alunos que se apresentavam em distorção

${ }^{4}$ A palavra aqui está sendo usada em seu sentido próprio, etimológico: aquilo que pode ser percebido pelos sentidos. 
idade/série - ferem o princípio da competência para a adequação contextual, que está relacionado à adequação ao gênero textual/discursivo proposto para a produção. Apesar de apresentarem características das fábulas, faltou-lhes a relação com um mundo fictício no interior de suas ideias, que é peculiar às fábulas.

Pelas análises das produções (inicial e final) dos alunos, percebemos que a proposta aplicada abriu um espaço para o desenvolvimento da leitura crítica e da escrita, para a discussão em sala de aula e a troca de experiências, o que levou ao desenvolvimento da competência discursiva dos alunos. Entretanto, sabemos que o caminho é longo e que há muito ainda a percorrer, pois uma proposta como essa não se encerra em si mesma.

\section{CONSIDERAÇÕES FINAIS}

Nossas atividades foram norteadas por uma visão dialógica da língua. Ao final do processo, constatamos que os resultados obtidos foram satisfatórios, já que verificamos um desenvolvimento significativo das capacidades discursivas dos alunos a partir das atividades aplicadas na intervenção. Os exercícios propostos primaram pela interação com o outro, a troca de ideias e saberes, a discussão em sala de aula, diferente do que aconteceria, supomos, se tivéssemos adotado uma visão tradicional de trabalho com a leitura e a escrita. Como pontuamos, testamos e atestamos durante a intervenção que é através da interação autor-texto-leitor que o desenvolvimento da competência discursiva do sujeito acontece. $\mathrm{O}$ interesse dos alunos por atividades (tão simples até), como as que foram propostas, pode ser percebido logo no início da intervenção, quando alunos, por vontade própria, como resultado de nossa roda de conversa e do saco da leitura ${ }^{5}$, buscaram o empréstimo de livros na escola - comportamento que se repetiu durante a intervenção. Por isso, acreditamos que as práticas de leitura do texto literário em sala podem ser transformadas, valorizando a fruição, a troca de experiências, o compartilhamento e a interação, a fim de favorecer o letramento dos alunos.

Contudo, durante a intervenção, verificamos que alguns pontos da SD precisam ser revisados, a fim de que se possa proporcionar, se esse for o objetivo, a escrita do gênero fábula; e tais cuidados devem ser observados na elaboração de futuros materiais aliados a essa proposta.

Devemos considerar que o ensino/aprendizagem da escrita é um processo e, para que seus objetivos sejam atingidos de maneira eficaz, demanda sempre tempo e muito trabalho. Apenas uma intervenção aplicada por um professor/pesquisador não surtirá efeitos. É necessário persistência, perseverança em um trabalho que se faça reflexivo, crítico, diferenciado e comunicativamente relevante, o que justifica nossa escolha pelo $6^{\circ}$ ano, de maneira bastante específica, da Escola Estadual Antônio Carlos Pedreira, cuja nota no IDEB não tem sido das melhores, a fim de começar a atingir o problema a partir do momento em que ele se inicia no interior da escola. Assim, a partir dos resultados obtidos, a princípio, com nosso trabalho, acreditamos que as fábulas podem proporcionar

\footnotetext{
${ }^{5}$ Um saco de pano bordado, cheio de livros paradidáticos, que levamos para sala de aula no momento da sondagem, a fim de observarmos o interesse ou não dos alunos por livros.
} 
uma experiência enriquecedora da leitura do texto literário em salas de aula, pois possibilitam a interação, ao permitir que o leitor busque respostas, preencha espaços vazios, faça relações, questione, discuta, posicione-se.

Depois dessa experiência de trabalho com a sequência didática, posso ${ }^{6}$ concluir que o modelo é bastante pertinente para um ensino que vise o desenvolvimento dos alunos enquanto cidadãos críticos, reflexivos e autores do seu próprio dizer.

\section{REFERÊNCIAS}

ANTUNES, I. Lingua, texto e ensino: outra escola possível. São Paulo: Parábola Editorial, 2013.

. Análise de textos: fundamentos e práticas. São Paulo: Parábola Editorial, 2013.

BRASIL. Parâmetros Curriculares Nacionais: $3^{\circ}$ e $4^{\circ}$ ciclos do ensino fundamental: Língua Portuguesa. Brasília: MEC/SEF, 1998.

BAKHTIN, M. Estética da Criação Verbal. Trad. Paulo Bezerra. 6. ed. São Paulo: Editora WMF Martins Fontes, 2011.

COSSON, R. Letramento literário: teoria e prática. 2. ed. São Paulo: Contexto, 2014.

COSSON, R. SOUZA, R. J. de. Letramento Literário: uma proposta para a sala de aula. Disponível em:

<http://www.acervodigital.unesp.br/bitstream/123456789/40143/1/01d16t08.pdf>. Acesso em: 18 out. 2015.

COSTA-HÜBES, T. C; SIMIONI, C. A. Sequência Didática: Uma Proposta Metodológica Curricular de Trabalho com os Gêneros Textuais/Discursivos. In: BARROS, E. M. D; RIOS-REGISTRO, E. S. (Orgs.). Experiências com Sequências Didáticas de Gêneros Textuais. Campinas, SP: Pontes Editores, 2014. p. 15-39.

DEZOTTI, M. C. C. (Org.). A tradição da fábula: De Esopo a La Fontaine. São Paulo: Ed. UnB, 2003.

DOLZ, J.; NOVERRAZ, M.; SCHNEUWLY, B. Sequências didáticas para o oral e a escrita: apresentação de um procedimento. In: SCHNEUWLY, B; DOLZ, J. (Orgs.). Gêneros orais e escritos na escola. 2. ed. Campinas, SP: Mercado de Letras, 2010. p. 81-108.

\footnotetext{
${ }^{6}$ Aqui coloco-me em primeira pessoa do singular, pois senti a necessidade de destacar algumas impressões e possibilidades pessoais (doravante), enquanto professora de Língua Materna.
} 
FÁBULA. Disponível em: < http://pt.wikipedia.org/wiki/F\%C3\%A1bula>. Acesso em: 19 fev. 2015.

KLEIMAN, A. Texto \& Leitor: Aspectos Cognitivos da Leitura. 7. ed. Campinas, SP: Pontes, 2000.

KOCH, I. V. Ler e compreender os sentidos do texto. 3. ed. São Paulo: Contexto, 2011.

LOBATO, M. Fábulas. 3. ed. São Paulo: Editora Globo, 2012.

MARCUSCHI, L. A. Produção Textual, análise de gêneros e compreensão. São Paulo: Parábola Editorial, 2015.

SILVA, S. B. B. da et al. Leitura, multimodalidade formação de leitores. Salvador: UFBA, 2015.

SOARES, M. Letramento Literário: um tema em três gêneros. 2. ed. Belo Horizonte: Autêntica Editora, 2004.

Recebido em: 05/06/2017 Aprovado em: 23/07/2017 Publicado em: 01/02/2018 